\title{
On the Chemical Heterogeneity of Austenite in Maraging Steel
}

\author{
T.M. Makhneva ${ }^{1, a^{*}}$ and V.B. Dementyev ${ }^{1, b}$ \\ ${ }^{1}$ Udmurt Federal Research Center of the Ural Branch of the Russian Academy of Sciences", 34, \\ T. Baramzinoy St., Izhevsk, 426067, Russia \\ amah@udman.ru, bdemen@udman.ru
}

\begin{abstract}
Keywords: Maraging Steel, X-Ray Spectral Microanalysis, Phase Transformation, Liquation Austenite
\end{abstract}

\begin{abstract}
The change of Ni-, Cr-, $\mathrm{Cu}$ - contents in maraging steel composition occurring on heating in the subcritical and intercritical interval has been studied by the X-ray spectral microanalysis. Heating in the temperature range from $490^{\circ}$ to $550^{\circ} \mathrm{C}$ has resulted in increasing of Ni- $\mathrm{Cu}-$ concentrations in the liquation austenite when the latter is present in the steel structure as a consequence of several reasons (the large ingot, low level of forging reduction ratio, etc.). The significant enrichment of surface layers of austenite inclusions may probably occur if there are great differences between interphase and intraphase diffusion rates. By varying the thermal treatment and thus the Ni-diffusion in austenite it is possible to create austenite layers with different Ni-contents within a grain or massive martensite and it is also possible to control the material properties.
\end{abstract}

\section{Introduction}

Fe-Ni binary system state diagram, the kinetics of phase transformations in binary alloys in the "iron corner" of the diagram have been thoroughly studied since 1940-50 by [1-5].

The available information about Fe-Ni-system is quite sufficient except the definition of conditions of $\gamma \rightarrow \alpha$ - transformation process where one can observe the occurrence of decomposition, i.e. $\gamma \rightarrow \alpha+\gamma_{\text {ern }}$ where $\gamma_{\text {ern }}$ is nickel enriched austenite. All practically realized transformation models with $\gamma_{e r n}$-occurrence include two stages: (1) $\gamma \rightarrow M$ (on cooling bellow $M_{s}$ temperature), and (2) $M \rightarrow \alpha+\gamma_{\text {ern }}$ (sufficiently slow heating above $A_{H}$ - temperature).

Data on the study of the kinetics of $\gamma \rightarrow \alpha \rightarrow \gamma$ - transformations in iron-nickel alloys are given in [6-9]. Modern methods investigated the inhomogeneity of the $\gamma$-phase [6] as a result of the redistribution of system components between the phases [7]. In work [8] the assessment of the degree of heterogeneity in terms of nickel, depending on the mode of heat treatment of low-carbon chromium-nickel steel, was carried out.

Iinteresting data on $\gamma \rightarrow \alpha \rightarrow \gamma$ transformation kinetics study in Fe-Ni alloys have been presented in work [9]. The investigation of cosmic iron containing nickel has shown that realization of $\gamma \rightarrow \alpha \rightarrow \gamma_{\text {ern }}$ scheme is possible after million years under the condition of cooling rate in order of several degrees Celsius. In the work the new data on Fe-Ni diagram obtained by electron spectral analysis using $\varnothing 0,03 \mu \mathrm{m}\left(10^{-6} \mathrm{~m}\right)$ sonde are also presented. According to the refined data in the temperature range about $500^{\circ} \mathrm{C}$ and below this temperature the equilibrium line between $\alpha$ and $\alpha+\gamma$-regions becomes vertical increasing differences equilibrium nickel concentrations in $\alpha$ and $\gamma$ -phases. The authors as it seems to us have unreasonably averaged the values of nickel 
concentrations at the interphase boundary and inside the phases having thus distorted the positions of equilibrium lines.

Experience in the manufacture of forgings with a low reduction ratio has shown that their structure often contains residual nickel-enriched liquation austenite $\left(\gamma_{i q}\right)$. Despite multiple heatings to high enough temperatures for deformation $\left(1200^{\circ} \mathrm{C}\right)$ and the deformation with forging reduction ratio of 3 the homogeneous austenite is very often unobtainable [8]. It was of interest to study the chemical composition of liquation austenite in one of the maraging chromium-nickel steel.

Liquation austenite $\left(\gamma_{\text {liq }}\right)$ is a metastable phase. It is known that interphase equilibrium lines may be drawn further in the diagram area where the temperatures are lower and phase ratio is different. With these lines it is possible to identify metastable phase compositions.

Let us consider the alloy with $C_{o}$, concentration at the temperature $t$. For the bulk mass of the sample the heating temperature $t$ lies below $A_{s}$ temperature and the state is stable. When the liquation austenite is present in the steel, its structure presents some sort of conglomerate of two steel compositions, i.e. $C_{o}$, and $C_{1}$, or $C_{2}$ (fig. 1). For the 1iquation austenite two positions (above and below $A_{H}$ ) and two ways of transformation are possible under these conditions. In the case of liquation austenite composition corresponding to the point " 1 " with $C_{l}$ concentration (i.e. it is to the left from equilibrium line and lower than $A_{H}$ ) it is possible to expect two processes to occur: either the dissolution of liquation austenite, or the appearance at the interface of the concentration " $C_{3}$ ".

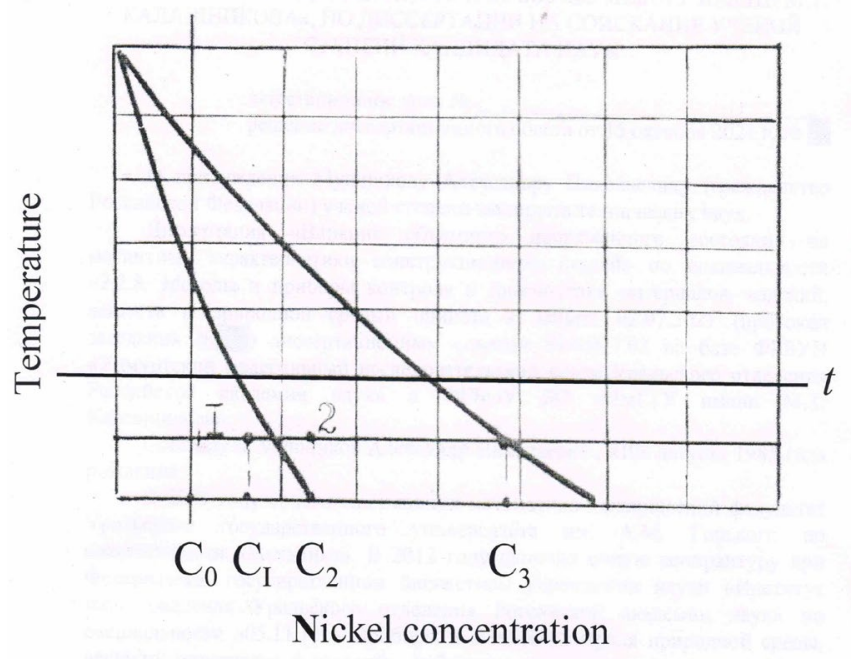

Fig. 1. Nickel heterogeneity formation (scheme)

Transformation $(\gamma \rightarrow \alpha)$ at the temperatures above $M_{s}$ practically cannot be realized. It would be therefore unreasonable to expect the disappearance of $\gamma_{\text {liq }}$ which has not been dissolved before at the higher heating's. The viability of $\gamma_{l i q}$ with $C_{2}$-composition locating at point " 2 " depends on its sizes. If the size of the area is more than the critical value then " $C_{3}$ " concentration must be expected to be at the interphase boundary. When the size of $\gamma_{l i q}$ is less than the critical value then one could expect the beginning of $\gamma \rightarrow \alpha$-transformation, and the probability of this process has already been discussed.

Thus, nickel concentration in the outer layers of the liquation austenite may be considerably increased if the duplex structure has artificially been formed. The actual degree of their enrichment 
must depend on Ni-diffusion rate from $\alpha$-phase and the rate of $\mathrm{Ni}$-atoms removal into the inner bulk of the area of $\gamma_{l i q}$. Hence, it is more probable to get nickel encroached layer at the lower temperatures as the difference of nickel content in $\alpha$ - and $\gamma$-phases, being in equilibrium, is increasing with decrease in the temperature and the rate of $\mathrm{Ni}$ atoms removal from the phase boundary into the austenite is decreasing.

Even in work [2] A.A. Popov has shown that the phase equilibrium at the interphase boundary is rapidly reached. The diffusion rate inside a grain is determined by the temperature of heating, it is possible therefore to change concentration gradients in the grain considerably by varying thermotemporal parameters. In relatively short period of time the great difference in nickel content may occur at the interphase boundary. The removal of Ni-atoms from the boundary in the austenite would be defined by the rate of diffusion. The formation of the considerable layer of the austenite at the interphase boundary at the lower temperatures is expected to take a certain period of time as well. When the thickness of the enriched layer is several lattice parameters, such a layer cannot be observed using the available methods. Consequently, the thickness of the nickel-enriched (detectable) layer should be of the order of $10^{-1} \mathrm{~m}$ with a probe diameter of $\varnothing 310-6 \mathrm{~m}$ and a nickel resolution of no worse than $0.1 \%$.

\section{Material and experimental procedure}

In order to check the above mentioned statements we have examined 08X15H5D2T steel having the 1iquation austenite in its structure. Samples of steel in the hotforged state have been heated up to $490^{\circ} \mathrm{C}, 520^{\circ} \mathrm{C}$ and $550^{\circ} \mathrm{C}$ with holding of 20 hours, and to $650^{\circ} \mathrm{C}$ with holding of 6 hours. Heating below $450^{\circ} \mathrm{C}$ has not resulted in any appreciable redistribution of nickel in the given steel. Polished sections have been exposed to weak electrolytic etching in 10\% oxalic acid. Chemical analysis of the structure components after regimes has been carried out with X-ray spectral microanalyses.

$\mathrm{X}$ ray spectrometer JEOL used in the present work has the sonde diameter of $310^{-6} \mathrm{~m}$ therefore much time is required to get the enriched layer of the indicated thickness at the temperatures about $500^{\circ} \mathrm{C}$. The examinations with the help of the magnetometer have shown that at the temperatures around $550^{\circ}$ the formation of the enriched austenite in the given steel starts after about 6 hours [10].

\section{Results and discussion}

$\mathrm{X}$-ray spectral microanalysis of the areas of the polished microsections, containing the liquation austenite, has shown approximately $1 \%$ increase in nickel in them, i. e. about 5,5\% for medium nickel-content in melting about 4,5\%. This minor, at the first sight, change in $\mathrm{Ni}$-content should not result in the qualitative changes in the structure. Our magnetometric investigations have shown that this is the nickel content interval for the given steel where $M_{s}$ temperature transition into the range of the lower temperatures (below $0^{\circ} \mathrm{C}$ ) has taken place. Indeed, the sub-zero treatment has resulted in the occurence of the martensite pattern on the surface of the 1iquation austenite areas.

In figures $2 \mathrm{~A}$ ) B) C) the results on mesuring $\mathrm{Ni}$ - $\mathrm{Cr}$ - $\mathrm{Cu}$ - concentrations in $\alpha$ and $\gamma$-phases are summerized. In fact, at the temperature $490^{\circ} \mathrm{C}$ the conditions are such that due to differences in diffusion rates of nickel at the interphase boundary and in the austenite the accumulation of $\mathrm{Ni}$ in the surface layer of the austenite area occurs. With the temperature increase from $490^{\circ} \mathrm{C}$ to $650^{\circ} \mathrm{C}$, with the acceleration in the intraphase diffusion and decrease in the magnitude of the equilibrium concentration of nickel in the austenite the nickel "peak" is smearing and gradually the change in nickel concentration is normalized and becomes characteristic of the monophase dissolusion. The exposed appreciable copper diffusion from $\alpha$-into $\gamma$-phase is of interest. Copper concentration sometimes is twice as big as that in ferrite. Probably, this diffusion is made easier by isomorphism 
of copper and austenite. The change of chromium concentration occurs gradually. The inner layers of the 1iquation austenite contain approximately $1 \%$ less of chromium than the adjacent $\alpha$-phase does.

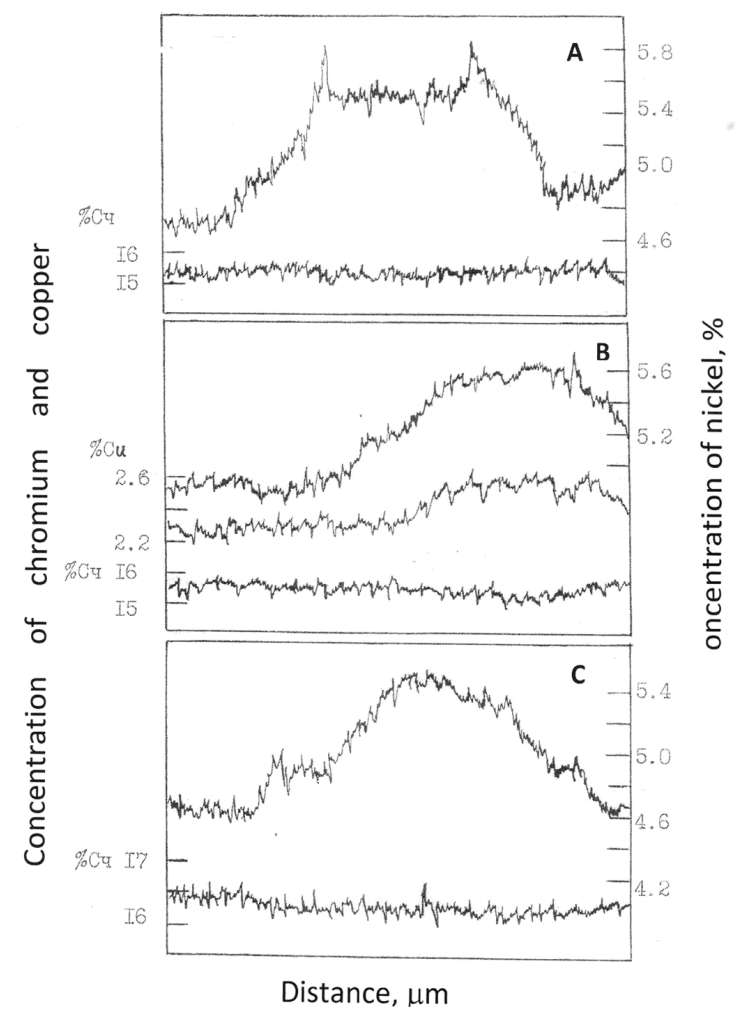

Fig. 2. Redistribution of nickel, copper and chromium during heating of $08 K h 15 N 5 D 2 T$ steel into the two-phase $\alpha+\gamma$-region.

$A-490^{\circ} \mathrm{C}, 20 \mathrm{~h} ; \mathrm{B}-520^{\circ} \mathrm{C}, 20 \mathrm{~h} ; \mathrm{C}-550^{\circ} \mathrm{C}, 20 \mathrm{~h}$.

Enrichment of austenite with nickel in the two-phase region occurs in the steel under study, both in the presence of liquation [8] and without it, stabilizing the $\gamma$-phase [11]. This is also evidenced by the data of [7], in which the morphology study of $\alpha \rightarrow \gamma$-transformation in massive martensite carried out by V.I. Zeldovich has shown that the interphase boundary may lie inside the massive martensite itself [7]. Electron microscopy study of steel structure after heating to $650^{\circ} \mathrm{C}$ with 6 hours holding, which causes the formation of about $50 \%$ of austenite and after cooling $25-30 \%$ of austenite remains, has shown the formation of the duplex structure. Outer layers of the structure element have remained in the austenite state alter cooling, and inner layers have been in the martensite state

Thus the variation of the thermotemporal parameters under the thermal treatment $08 \mathrm{X} 15 \mathrm{H} 5 \mathrm{D} 2 \mathrm{~T}$ steel has made it possible to obtain different and among them anomalous distributions of nickel in the steel microstructure and to form the duplex structure. On the slow heatings the liquation austenite is "replenished" by nickel, starting from the subcritical temperatures, this may result in increasing of the austenite stability.

\section{References}

[1] N.P. Allen, C.J. Early, Iron Steel Inst., 28 (1950) 455. 
[2] A.A. Popov, Diffusion movement of the border of the phase separation, Phase transformations in iron-carbon alloys. Mashgiz. (1950) 18-35.

[3] E. Scheil, Über die Irreversibilität der Eisen-Nickel-Legierungen, Archiv für das Eisenhüttenwesen 24. Jahrgang. Heft 3/4- Märtz / Ahril (1953).

https://doi.org/10.1002/srin.195301444

[4] Ya.M. Golovchiner, DAN SSSR. 107 (1953)109.

[5] Ya.M. Golovchiner, Problems of metal science and physics of metals, Metallurgizdat. 7. (1962) 281.

[6] V.A. Shabashov, V.V. Sagaradze, E.E. Yurikov, A.V. Savelyeva, Mesbauer and electron microscopic studies in iron-nickel alloys, FMM. 44.5 (1977)1060-1070.

[7] V.I. Zeldovich, V.D. Sadovsky, Redistribution of components between $\alpha$-and $\gamma$-phases at $\alpha \rightarrow \gamma$ - transformation in iron-nickel alloys, FMM. 284 (1969) 715-722.

[8] T.M. Makhneva, Investigation of chemical heterogeneity with respect to nickel and chromium in the structure of steel 08Kh15N5D2T, IM Ural Branch of the Russian Academy of Sciences. "Chemical Physics and Mesoscopy". 15-1 (2013) 91-100.

[9] A.D. Romig, J.I. Coldstein, Determination of the Fe-Ni and Fe-Ni-P Phase Diagrams at Low Temperatures $\left(700\right.$ to $\left.300^{\circ} \mathrm{C}\right)$. Metallurgical Transactions. 11.7 (1980) 1151-1159. https://doi.org/10.1007/BF02668139

[10] E.S. Makhnev, T.M. Makhneva, Reverse martensitic transformation in steel VNS-2USH, Martensitic transformations in metals and alloys. Sat. report int. conf. Kiev: Naukova Dumka, 1979, pp. 180-184.

[11] T.M. Makhneva, A.A. Sukhikh, V.B. Dement'ev, Inverse martensitic $\alpha \rightarrow \gamma$ - transformation in nanostructured maraging steels, Metal Science and Heat Treatment, Kluwer Academic/Plenum Publishers (United States) (2017) 1-6. 